\title{
Idarucizumab as Antidote to Intracerebral Hemorrhage under Treatment with Dabigatran
}

\author{
Valentin Held $^{\mathrm{a}}$ Philipp Eisele ${ }^{\mathrm{a}}$ Christoph C. Eschenfelder ${ }^{\mathrm{b}}$ \\ Kristina Szabo ${ }^{a}$ \\ ${ }^{a}$ Department of Neurology, Universitätsmedizin Mannheim, Heidelberg University, \\ Mannheim, Germany; ${ }^{b}$ Medical Affairs Germany, Boehringer Ingelheim Pharma GmbH \& \\ Co KG, Ingelheim am Rhein, Germany
}

\section{Keywords}

Intracerebral hemorrhage $\cdot$ Anticoagulant $\cdot$ Dabigatran $\cdot$ Idarucizumab $\cdot$ Antidote $\cdot$ Stroke

\begin{abstract}
Background and Purpose: Non-vitamin K anticoagulants (NOAC) such as dabigatran have become important therapeutic options for the prevention of stroke. Until recently, there were only nonspecific agents to reverse their anticoagulant effects in a case of emergency. Idarucizumab, an antibody fragment targeting dabigatran, is the first specific antidote for a NOAC to be approved, but real-world experience is limited. Methods: We report two cases of patients on dabigatran with acute intracerebral hemorrhage who received idarucizumab. $\boldsymbol{R e}$ sults: In both cases, idarucizumab promptly reversed the anticoagulant effect of dabigatran and there was no hematoma expansion in follow-up imaging. Conclusions: In addition to clinical and preclinical studies, our cases add to the experience regarding the safety and efficacy of idarucizumab. They show that idarucizumab may be an important safety option for patients on dabigatran in emergency situations.

(C) 2016 The Author(s)

Published by S. Karger AG, Basel
\end{abstract}




\section{Case Reports in Neurology} \begin{tabular}{l|l}
\hline Case Rep Neurol 2016;8:224-228 \\
\hline DOI: 10.1159/000452096 & $\begin{array}{l}\text { C 2016 The Author(s). Published by S. Karger AG, Basel } \\
\text { www.karger.com/crn }\end{array}$ \\
\hline
\end{tabular}

Held et al.: Idarucizumab as Antidote to Intracerebral Hemorrhage under Treatment with Dabigatran

In 2010, the FDA approved the direct thrombin inhibitor dabigatran (Pradaxa) for the prevention of stroke and systemic embolism in patients with atrial fibrillation. Thereafter, factor Xa inhibitors (rivaroxaban, apixaban, and recently edoxaban) were also approved. Both factor IIa and factor Xa inhibitors display the newly formed class of non-vitamin K oral anticoagulants (NOAC). Due to the lack of specific antidotes to rapidly reverse the anticoagulant effect of NOACs, in cases of medical emergency, the use of nonspecific agents with limited efficacy is still the method of choice for factor Xa inhibitors, where specific reversal agents are still in development.

Idarucizumab (Praxbind), the first novel antidote for a NOAC specifically antagonizing dabigatran, was recently approved by the US FDA in October and by the EMA in November 2015. We report two cases of patients on dabigatran with intracerebral hemorrhage who received idarucizumab.

\section{Case 1}

A 74-year-old woman was admitted with an acute onset of aphasia and right-sided hemiparesis (NIHSS on admission 18). She was last seen normal about $3 \mathrm{~h}$ earlier. Her medical history included atrial fibrillation, for which she had taken dabigatran $110 \mathrm{mg}$ b.i.d. (the last dose about $9 \mathrm{~h}$ earlier). Further concomitant diseases included coronary heart disease and arterial hypertension. Blood pressure on admission was 180/80 $\mathrm{mm} \mathrm{Hg}$ but rose subsequently to $230 / 120 \mathrm{~mm} \mathrm{Hg}$. CT on admission (Fig. 1) showed a large $(6.2 \times 3.9 \times 5.8 \mathrm{~cm})$ lobar intracerebral hemorrhage in the left hemisphere. Laboratory findings showed very mildly elevated activated partial thromboplastin time (aPTT) of $30.3 \mathrm{~s}$ (normal range 15$30 \mathrm{~s}$ ) and a moderately elevated thrombin time (TT) of $81.6 \mathrm{~s}$ (normal range 17-24 s). Creatinine was slightly elevated at $103.8 \mu \mathrm{mol} / \mathrm{L}$ (normal range $58.1-95.92 \mu \mathrm{mol} / \mathrm{L}$ ), and creatinine clearance estimated according to the formula of Cockcroft and Gault was $66.8 \mathrm{~mL} / \mathrm{min}$. Dabigatran concentration on admission was measured by the Hemoclot ${ }^{\circledR}$ test and showed a result below the sensitivity range of the test $(50 \mathrm{ng} / \mathrm{mL}$ ). Idarucizumab was administered 45 min after arrival in the ER; when measured $3 \mathrm{~h}$ later, aPTT and TT were in the normal range (23.9 and $20.6 \mathrm{~s}$, respectively). The patient was admitted to our stroke unit. Elevated blood pressure was treated aggressively to a target of below $140 \mathrm{~mm} \mathrm{Hg}$ systolic BP. Further diagnostics did not reveal any cause of hemorrhage other than elevated blood pressure and anticoagulant treatment. During the clinical workup, no hematoma growth was detected. Sixteen days after admission, she was transferred to a rehabilitation unit. By that time, the aphasia had partially receded, but hemiparesis was still pronounced (NIHSS 9).

\section{Case 2}

A 76-year-old patient was brought to the emergency room intubated due to progressive decrease of consciousness and left hemiparesis (NIHSS 32). He had a medical history of colon cancer, hypertension, and coronary heart disease. He was on dabigatran $110 \mathrm{mg}$ b.i.d. due to atrial fibrillation since 2012. Upon arrival, he presented with a hypertensive crisis (>200 mm Hg systolic) and CT revealed a right subcortical hemorrhage $(3.7 \times 3.5 \times 2.0 \mathrm{~cm})$ with severe ventricular involvement (Fig. 2). Laboratory findings showed mildly elevated aPTT of $32.6 \mathrm{~s}$ (normal range 15-30 s) and a moderately elevated TT of $77.8 \mathrm{~s}$ (normal range 17-24 s); dabigatran concentration was not measured in this patient. Renal function was 


\section{Case Reports in Neurology}

Held et al.: Idarucizumab as Antidote to Intracerebral Hemorrhage under Treatment with Dabigatran

normal (creatinine $96.8 \mu \mathrm{mol} / \mathrm{L}$, gender- and age-specific normal range 71.3-126.7 $\mu \mathrm{mol} / \mathrm{L}$, estimated creatinine clearance $64.6 \mathrm{~mL} / \mathrm{min}$ ).

Elevated blood pressure was lowered aggressively, idarucizumab was administered $1 \mathrm{~h}$ after admission, and an external ventricular drain was inserted. The repeat measure of aPTT at $3 \mathrm{~h}$ after administration of idarucizumab showed a normal value (28.3 s). After 2 weeks on the intensive care unit, the patient was weaned and extubated. On follow-up in week 4 , he had partially recovered; he was able to speak one-word sentences, but hemiparesis was still pronounced (NIHSS 22). Also this patient did not show evidence of hematoma expansion.

\section{Discussion}

Idarucizumab is a humanized antibody fragment specifically binding to dabigatran. It has been shown to rapidly reverse the anticoagulant effect of dabigatran in healthy volunteers [1], and also in the "The Reversal Effects of Idarucizumab on Active Dabigatran" (REVERSE AD) study, a phase 3, global, prospective cohort study (http://www.clinicaltrials.gov; NCT02104947) involving patients on dabigatran requiring urgent intervention/surgery or experiencing life-threatening or uncontrolled bleeding [2]. Preliminary data are promising [3]. Our cases demonstrate that the anticoagulant effect of dabigatran can be promptly and effectively counteracted by idarucizumab under "real world conditions", thus adding a specific safety option for emergency situations for patients on dabigatran. Further research is required for a specific antidote for factor Xa inhibitors as the clinical development program is still ongoing and approval is pending; however, it would also add further safety to patients on factor Xa inhibitors. Both cases also demonstrate the role of hypertension in patients taking oral anticoagulation and the development of intracerebral hemorrhage.

The two presented cases are in line with a recent subgroup analysis of the RE-VERSE AD trial focusing on 18 patients with intracranial hemorrhage [4]. This subgroup analysis aimed at analyzing the ability of idarucizumab to reverse the anticoagulant effects of dabigatran on the basis of an interim analysis. The analysis showed a rapid reversal of the anticoagulant activity and a mortality rate similar to patients without intracerebral hemorrhage included in the RE-VERSE AD trial.

\section{Statement of Ethics}

The authors have no ethical conflicts to declare.

\section{Disclosure Statement}

C.C. Eschenfelder is an employee of Boehringer Ingelheim. The other authors report no conflicts. 


\section{Case Reports in Neurology}

\begin{tabular}{l|l}
\hline Case Rep Neurol 2016:8:224-228 \\
\hline DOI: 10.1159/000452096 & $\begin{array}{l}\text { C 2016 The Author(s). Published by S. Karger AG, Basel } \\
\text { www.karger.com/crn }\end{array}$ \\
\hline
\end{tabular}

Held et al.: Idarucizumab as Antidote to Intracerebral Hemorrhage under Treatment with Dabigatran

\section{References}

1 Glund S, Stangier J, Schmohl M, Gansser D, Norris S, van Ryn J, et al: Safety, tolerability, and efficacy of idarucizumab for the reversal of the anticoagulant effect of dabigatran in healthy male volunteers: a randomised, placebo-controlled, double-blind phase 1 trial. Lancet 2015;386:680-690.

-2 Pollack CV, Reilly PA, Bernstein R, Dubiel R, Eikelboom J, Glund S, et al: Design and rationale for REVERSE AD: a phase 3 study of idarucizumab, a specific reversal agent for dabigatran. Thromb Haemost 2015;114:198-205.

-3 Pollack CV, Reilly PA, Eikelboom J, Glund S, Verhamme P, Bernstein RA, et al: Idarucizumab for dabigatran reversal. N Engl J Med 2015;373:511-520.

4 Bernstein RA, Pollack CV Jr, Weitz JI, et al: Abstract 213. Effect of idarucizumab on intracranial bleeding in dabigatran-treated patients: initial results from RE-VERSE AD. Presented at the International Stroke Conference 2016, February 17-19, 2016, Los Angeles.

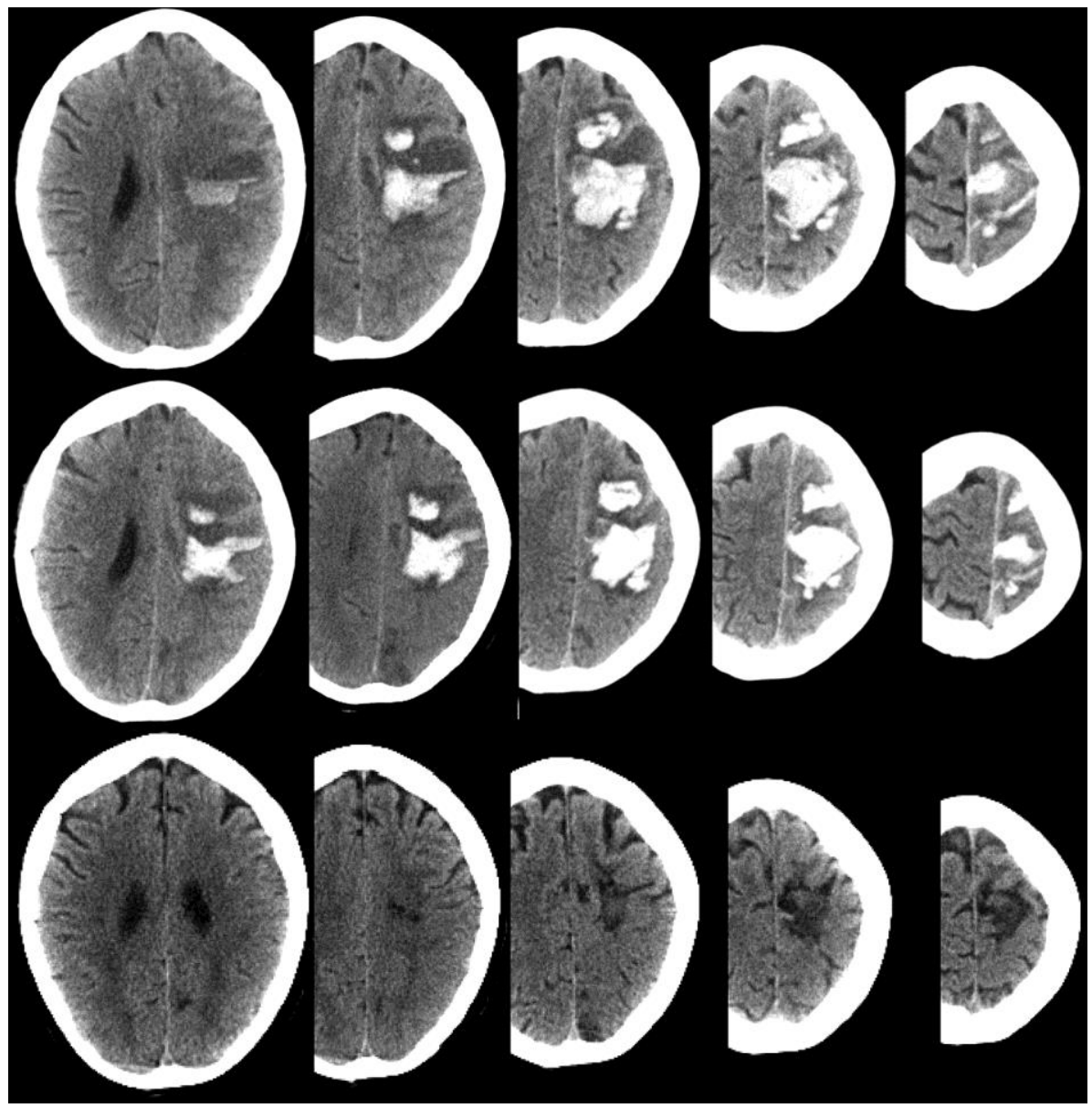

Fig. 1. Case 1. Upper row: CT scan on admission shows extensive left lobar hemorrhage and sulcal blood. Middle row: follow-up CT about $10 \mathrm{~h}$ after admission. The patient's head was tilted during the scan, and slices are chosen to best compare the extent of hemorrhage, which is stable. Bottom row: on follow-up CT at week 12, hemorrhage has completely resolved. 


\section{Case Reports in Neurology}

\begin{tabular}{l|l}
\hline Case Rep Neurol 2016:8:224-228 \\
\hline DOI: 10.1159/000452096 & $\begin{array}{l}\text { ○ 2016 The Author(s). Published by S. Karger AG, Basel } \\
\text { www.karger.com/crn }\end{array}$ \\
\hline
\end{tabular}

Held et al.: Idarucizumab as Antidote to Intracerebral Hemorrhage under Treatment with Dabigatran

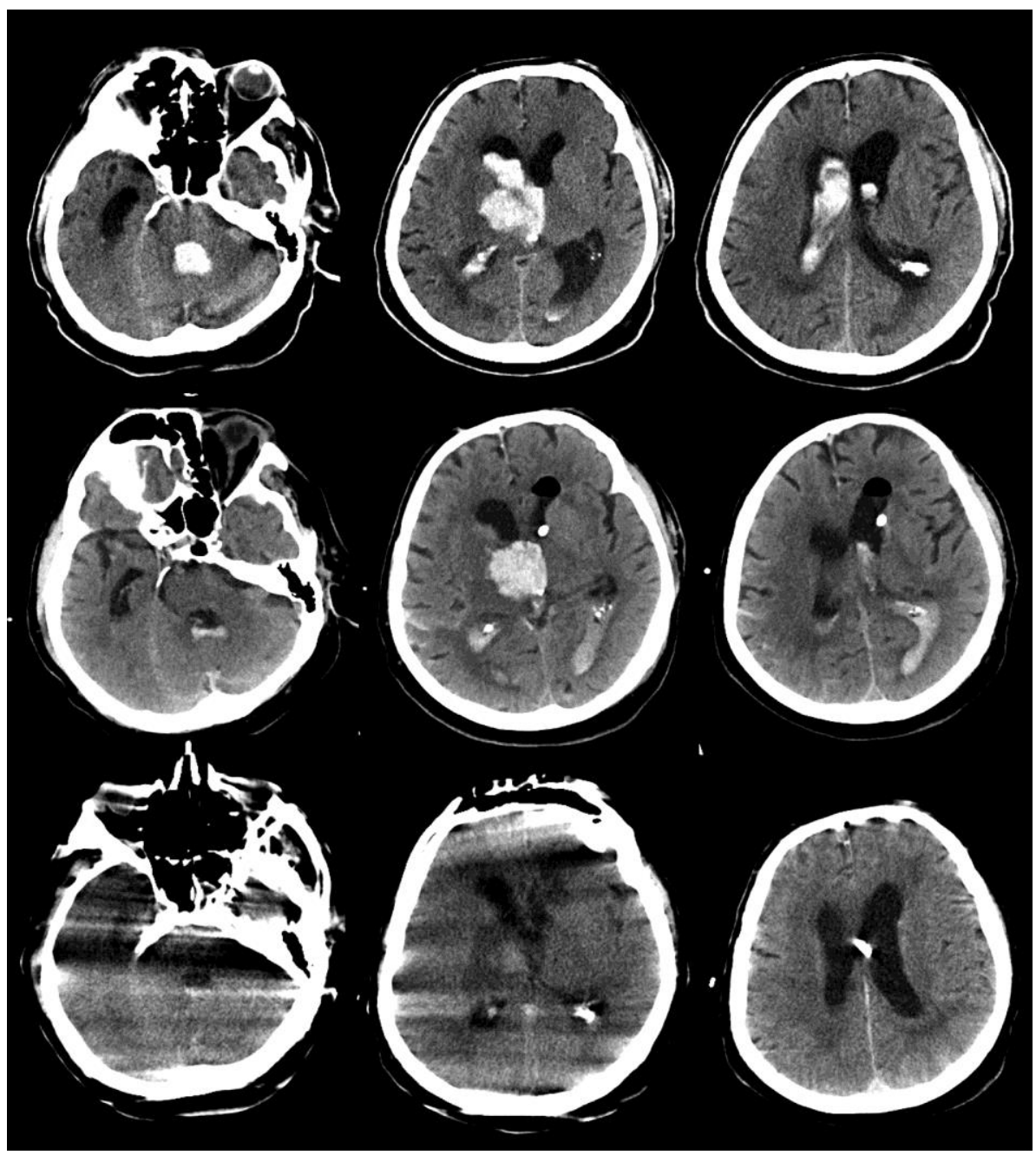

Fig. 2. Case 2. Upper row: CT scan on admission shows hemorrhage originating from the right basal ganglia with extensive ventricular involvement and enlargement of the lateral ventricles. Middle row: follow-up on day 2 after insertion of an external ventricular drain shows stable hematoma size. Bottom row: follow-up CT performed at week 3 with resorption of hemorrhage, perifocal edema, and reduction of spaceoccupying effect. 